\title{
PERGUNTAS AUTORITÁRIAS: A QUESTÃO DO MÉTODO, AS MONOGRAFIAS E O FILOSOFAR. ${ }^{1}$
}

\author{
Gonzalo Armijos Palacios*
}

\begin{abstract}
RESUMO
Neste artigo discuto a relação entre as perguntas autoritárias e sua influência na forma de concebermos o trabalho filosófico na academia brasileira, em geral, assim como o que entendemos por método e por trabalhos finais ou monografias de final de curso.

Palavras-chaves: Metodologia. Monografia de final de curso. Fazer filosofia.

ABSTRACT

In this article I discuss the relationship between authoritative questions and their influence on the way we conceive to be philosophical work in the Brazilian academy, in general, and what we understand by method and by term-papers and monographic papers.
\end{abstract}

Keywords: Methodology. Monographic paper. Doing philosophy.

Num evento sobre o ensino de Filosofia e Sociologia me perguntaram sobre o papel que deve ter o professor. A pergunta me deixou perplexo. Há determinadas ocasiões em que percebemos

1 Partes deste artigo apareceram no Jornal Opção, semanário em que mantenho a coluna "Idéias".

Professor Doutor do Departamento de Filosofia da Universidade Federal de Goiás. E-mail: garmijos@cultura.com.br 
que, em algum sentido importante, não estamos em sintonia com o mundo. O leitor já deve ter passado pela experiência de perceber que outros dão por evidente ou absolutamente verdadeiro o que, no fundo, é altamente questionável. Não é a primeira vez que isso acontece. Quando era estudante da graduação em filosofia e estava prestes a me formar, me perguntaram sobre quem iria escrever a dissertação. Naquela ocasião, também, fiquei entre mudo e boquiaberto. Pois naquele instante percebi o que talvez fosse uma obrigação de todo estudante de filosofia: escrever a dissertação, necessariamente, sobre alguém. Na verdade, não tinha passado pela minha cabeça que era minha obrigação escrever sobre alguém, como outros achavam - e, lamentavelmente, ainda acham - mas sobre algum problema filosófico que me incomodasse, me preocupasse e merecesse alguma tentativa de solução racional. Eventualmente, poderia escrever contra alguém - contra as idéias de algum filósofo, isto é - mas não necessariamente sobre esse pensador.

Para minha tristeza, muitos continuam pensando que do que se trata é de se escrever monografias, em filosofia, que sejam única e exclusivamente sobre as idéias de algum famoso pensador. A ninguém parece ocorrer que um estudante possa ter o direito e as condições para querer discutir as idéias de um clássico da filosofia. Já tive de presenciar inúmeras defesas de monografias finais em que os estudantes se limitam a reproduzir as idéias dos autores que seus orientadores estudam - para beneplácito e orgulho desses orientadores, diga-se de passagem. E os estudantes, tanto da graduação como na pós-graduação, continuam a escrever monografias finais nas quais, sem o menor constrangimento, anunciam nas introduções que nos seus trabalhos perseguem "entender" as idéias de tal autor ou autora. Penso que isso seria um mérito se tais autores tivessem escrito em hieróglifos por nós desconhecidos, mas o fato é que não é assim. Esses famosos pensadores, idolatrados por certos professores e seus estudantes, escreveram em línguas conhecidas e usando escritas conhecidas. Portanto, não há grande mérito em entender o que, para começar, escreveram e publicaram precisamente com esse desejo: o de serem

Educ. e Filos., Uberlândia, v. 22, n. 44, p. 101-114, jul./dez. 2008. 
compreendidos. De qualquer forma, na época em que me fizeram a pergunta de "sobre quem" iria escrever a monografia, minha reposta foi: "mas as monografias devem necessariamente ser escritas sobre alguém? Não podem ser escritas para se tentar resolver algum problema?" Dei ouvidos surdos à obrigação que estava implícita na pergunta e redigi minha monografia sobre um problema que me preocupava na época - o que é ideologia.

Numa outra ocasião, já radicado no Brasil, e vindo de um evento de filosofia em São Paulo, um colega de outra universidade, ante alguma afirmação minha, me perguntou espantado "mas há soluções na filosofia!?". Confesso que fiquei tanto ou mais espantado ainda do que ele. Pois, se não houver soluções para os problemas filosóficos, que estou fazendo na minha profissão? E por que os filósofos lutaram e lutam para resolvê-los escrevendo tantas páginas e tantos livros na procura delas? Pois que há soluções aos vários problemas, há. Que não haja consenso sobre se são ou não soluções, ou se tais soluções são corretas, esse é outro problema. Mas que os filósofos apresentaram soluções para seus problemas, e continuam apresentando, isso é inegável.

O que me leva ao assunto inicial sobre meu suposto papel como professor. É um papel? São vários? Quem é que decide qual deveria ser meu papel? A instituição? O Ministério da Educação? O governo? Algum autor consagrado que recebera o respaldo da maioria de educadores ou das instituições de ensino? Alguma resolução votada e aprovada em algum colegiado, alguma lei aprovada por algum parlamento? Talvez o meu papel seja muito vago: incentivar nos estudantes a procura da verdade.

Como podem ver, há perguntas autoritárias que exigem respostas autoritárias. Respondo, então, como respondi hoje: não cumpro nenhum papel, pois não assumo nem assumi nenhum que me tenha sido imposto por ninguém. E o que faço, faço porque estou convencido de que é o que devo fazer, e da forma em que acho que deve ser feito, sem estar pedindo licença a ninguém nem me amparando na autoridade de ninguém. Talvez deva dizer que cumpro um antipapel: o de despertar nos estudantes de filosofia a necessidade de não assumir o papel secundário de se limitar a ser

Educ. e Filos., Uberlândia, v. 22, n. 44, p. 101-114, jul./dez. 2008 
mero comentador de filósofos consagrados e de se assumir como filósofos.

\section{A falácia do método único}

O autoritarismo por trás de perguntas sobre os supostos papéis que devemos desempenhar aparece, também, quando as pessoas pensam que devemos agir de determinadas maneiras. Isto é, que devemos fazer as coisas de uma e única maneira porque, de algum modo misterioso, as próprias coisas exigem que lidemos com elas de um único modo. Isto é muito comum na academia, lamentavelmente. Perguntas autoritárias, e que exigem respostas autoritárias, são: 'qual é o método para se escrever uma monografia?' e 'qual é o método para se desenvolver uma pesquisa?'. Essas perguntas pressupõem a existência de um único modelo, de uma forma privilegiada e exclusiva, isto é, para escrevermos monografias ou levarmos a cabo pesquisas. Não posso deixar de mencionar como foi libertadora a leitura de uma obra que apareceu nos anos 70, escrita pelo filósofo da ciência austríaco Paul Feyerabend, cujo título diz tudo: Contra o método. Naquela obra, Feyerabend defende uma tese polêmica e propõe uma posição epistemológica provocadora: o anarquismo epistemológico. A tese central, talvez a única, de tal epistemologia anarquista é: "tudo vale". A inadmissibilidade da tese, contudo, não torna a posição menos instigante. Pois se é verdade que resulta inaceitável que possamos acreditar que tudo vale, o outro extremo também é falso: só vale um método privilegiado.

O método deve ser entendido como um caminho que nos leva de algum lugar a outro. Dessa forma, o caminho que escolhamos estará determinado por inúmeros fatores. Entre eles temos: a área em que queremos desenvolver a pesquisa ou redigir nossa monografia, as motivações e as circunstâncias que nos levaram aos problemas que queremos resolver e, por último, os objetivos que perseguimos. Tudo isso, obviamente, vai afetar a maneira que escolhemos para desenvolver nossa busca e redigir nosso trabalho.

Não podemos, no entanto, esquecer que essas considerações

Educ. e Filos., Uberlândia, v. 22, n. 44, p. 101-114, jul./dez. 2008.

104 
vão estar inseridas num contexto social e histórico determinado e que, num sentido ou noutro, estaremos influenciados pelo que gostaria de chamar, parafraseando uma velha expressão, de 'noções vulgares'. E acrescentaria: noções vulgares dos nossos pares e da nossa sociedade. Explico com um exemplo. Vamos supor que, motivados pela série interminável de escândalos na política brasileira, queiramos desenvolver uma pesquisa e redigir uma monografia sobre financiamento de campanha. Dificilmente nessa pesquisa deveremos considerar uma defesa do financiamento ilimitado das campanhas baseado no princípio da liberdade de expressão. O leitor deve estar perguntando: que tem a ver uma coisa com a outra? Eu também faria a mesma pergunta. Mas nos Estados Unidos, as grandes corporações defendem o financiamento ilimitado nas campanhas políticas com o argumento de que isso faz parte da liberdade de expressão, garantida pelas leis daquele país. O que, avaliado objetivamente, dificilmente pode ser sustentado, por irrelevante, e por não passar de um artifício escuso para o poder econômico controlar as decisões dos políticos no parlamento norte-americano. Vejamos outro exemplo: qualquer pesquisa sobre células-tronco, feitas nos Estados Unidos, deve levar em conta a legislação que os conservadores desse país conseguiram promulgar por motivos religiosos. Os exemplos mostram que os métodos de pesquisa, incluída a redação da própria pesquisa de seus resultados, dependem de fatores que vão do puramente teórico ao ideológico.

Pois, em muitos casos, o que se considera politicamente correto obriga a que, digamos, destros desenvolvam suas pesquisas como se fossem canhotos, que canhotos escrevam as suas com a destra e que, em definitivo, as habilidades e inclinações naturais de cada pesquisador se curvem frente às imposições de um meio dominado pelo autoritarismo e o tradicionalismo.

Ao escrever uma monografia devemos fazer várias escolhas. Dependendo do meio acadêmico em que nos encontremos, e o tipo de orientação que tenhamos, nossas escolhas serão mais ou menos amplas. Teríamos, em princípio, a possibilidade de defender idéias majoritariamente nossas. $\mathrm{O}$ que não implica o desconhecimento 
da tradição e dos clássicos. Aspecto que, no meu ver, é fundamental. E torna-se mais importante, ainda, quando se trata de refletir sobre questões tratadas pelos filósofos consagrados, sejam do passado ou do presente. Assim, poderemos fazer uma monografia em que defendamos nossa visão de um determinado problema - em cujo caso vão entrar em jogo nossas próprias idéias -, avaliar as teses, problemas ou soluções de algum pensador clássico do presente ou do passado - razão pela qual o conhecimento da tradição filosófica se torna indispensável - ou, finalmente, interpretar as idéias de um outro filósofo. (Denominarei esta última opção 'hermenêuticohistoriográfica'.)

No último caso temos, também, opções. Podemos desenvolver um trabalho hermenêutico ou exegético de alguma passagem pouco trabalhada, pouco conhecida ou considerada sem importância - e até por isso pouco pesquisada - , ou nos debruçar sobre alguma passagem ou texto considerados importantes e, por isso mesmo, muito estudados e sobre os quais haveria farto material bibliográfico. Nesta escolha, naturalmente, corre-se o risco de não se ter nada novo a dizer.

Sejam quais forem, gostaria que os estudantes de filosofia tivessem, realmente, todas essas opções e pudessem fazer livremente suas escolhas. A academia filosófica brasileira, por confissão de uns dos seus representantes mais ilustres, Osvaldo Porchat, reconhece que coibiu, por muito tempo, o que considerava - e talvez ainda se considere - uma veleidade, isto é, permitir que o estudante trabalhe naquilo que realmente lhe interessa e possa desenvolver suas próprias idéias, sem necessariamente apegar-se à tradição. Acredito serem possíveis bons trabalhos monográficos nos diversos modos de se fazer uma dissertação.

No caso de termos de avaliar uma monografia que escolhe a linha interpretativa surgem várias linhas de análise. Nessa linha devemos fazer as seguintes considerações e perguntas. Dirige-se esse trabalho a discutir alguma interpretação feita sobre as teses do autor ou autores escolhidos? Entra o estudante na discussão de alguma tensão interpretativa sobre o trabalho do autor? Em muitos casos, o estudante se limita a estudar as idéias do autor. Sendo

Educ. e Filos., Uberlândia, v. 22, n. 44, p. 101-114, jul./dez. 2008. 
esse o caso, como apresenta as idéias do autor? Expõe as motivações e os problemas que levaram o autor ao desenvolvimento de suas teses - motivações não explícitas pelo próprio autor - ou se limita a simplesmente reproduzir as conclusões às que o autor chegou?

Num trabalho de viés hermenêutico-historiográfico, o valor consiste, por exemplo, em mostrar a relação entre determinados eventos históricos e certas idéias, mostrando-se como esses eventos levantaram problemas que o autor teria visto como uma necessidade resolver. Existe, também, a possibilidade de não serem eventos históricos que motivaram a problematização do autor, mas determinadas visões sobre tais eventos. Assim, um trabalho hermenêutico-historiográfico pode explorar as tensões entre as idéias do autor e as idéias do seu tempo, ou entre suas idéias e as de outros autores.

Existe, também, outra possibilidade, a de mostrar a tensão entre as próprias idéias do autor - se partimos da base que é impossível para os seres humanos, mesmo para os grandes filósofos, apresentar seus textos de maneira absolutamente consistente ou de forma totalmente clara. Podemos, então, perguntar também se o trabalho explora alguma tensão interna ao texto do autor. Isto é, se o estudante percebe algum - mesmo que seja pequeno - problema no desenvolvimento, na apresentação, ou nas conclusões às que chega o autor.

E há, de início, uma consideração a ser feita: para que escrevemos uma monografia ou um texto acadêmico qualquer?. Não pode ser, simplesmente, para sermos aprovados e termos um diploma. Essa é uma razão importante. Mas, qual é a razão teórica. Naturalmente, dependendo do tipo de trabalho monográfico escolhido dentre as opções mencionadas, as respostas serão diferentes. No caso de uma monografia hermenêuticohistoriográfica, qual seria o objetivo (o "para-quê") que complementaria o porquê teórico do trabalho? Obviamente, não pode ser só para conhecer as idéias do autor, que já deviam ter sido conhecidas antes de se começar a monografia - idéias aprendidas no tempo em que deviam ser aprendidas, nas diversas

Educ. e Filos., Uberlândia, v. 22, n. 44, p. 101-114, jul./dez. 2008 
disciplinas da graduação. Há inúmeras razões para trabalharmos hermeneuticamente os filósofos. Há tantas motivações como pessoas interessadas neste ou naquele autor. Assim, deve haver um número ilimitado de razões que justificariam sua leitura. Suponho que se lê algum autor para se chegar a algum lugar. Por isso devemos nos perguntar a que lugar quer chegar o estudante e que lugar é esse.

Quando era estudante da graduação, o professor Dr. Rodolfo Agoglia Volpatti, exilado pelo governo argentino e que se encontrava nos seus sessenta anos, nos dizia o seguinte: em qualquer trabalho, por menor que seja, mesmo que seja o trabalho final de uma disciplina e não uma monografia final de curso, alguma idéia o estudante deve defender, que seja dele. Essa é sua contribuição, por menor que seja. Caso contrário, o trabalho se reduziria a um resumo - que pode ser muito bem feito - das idéias alheias, mas que não passa de um mero resumo. Dessa forma, então, devemos fazer esta pergunta ao lermos as monografias dos estudantes: qual é a idéia que justifica a leitura desse trabalho que não seja a mera informação sobre as teses do autor trabalhado? Por que seria importante ler o trabalho do estudante e não o texto do próprio autor? Seria o trabalho do estudante uma introdução esclarecedora de pontos obscuros - ou ausentes - na obra do autor? É uma interpretação sobre pontos problemáticos reconhecidos ou que passaram despercebidos pelo próprio autor? É uma interpretação que nos dá subsídios para compreender a modernidade, a contemporaneidade, talvez nossa situação atual? Em síntese, alguma contribuição um trabalho monográfico deve fazer que não seja a simples repetição, em outras palavras, das idéias do autor estudado.

Fiquei encantado, anos atrás, com a leitura de algumas obras do físico e matemático francês Henri Poincaré. Ele afirmava que mesmo entre os matemáticos podemos ver como suas habilidades influenciam suas pesquisas e trabalhos. Ele dizia, entre outras coisas, que basta abrir um artigo ou um livro escrito por algum matemático para notar suas habilidades e inclinações teóricas, isto é, para saber se tem uma inteligência espacial ou lógica. Um tenderá a apresentar

Educ. e Filos., Uberlândia, v. 22, n. 44, p. 101-114, jul./dez. 2008.

108 
seus resultados usando teoremas geométricos, já o outro o fará por meio de provas algébricas. É óbvio que ao segundo não devemos obrigar que desenvolvesse seu trabalho privilegiando a geometria, nem ao primeiro, de mentalidade espacial, que trabalhe com raciocínios algébricos. Cada um tem uma habilidade que deve ser aproveitada, habilidade que influenciará o modo de fazer o trabalho e a forma como chegará aos resultados desejados.

Certa vez fiz parte de uma banca de defesa de monografia de pós-graduação. Como sabemos, essas bancas são formadas com membros internos e um convidado de outra universidade. No caso, o professor convidado veio da Universidade Federal do Rio de Janeiro. O autor do trabalho monográfico não era meu orientando. Por isso, o que vou contar nada tem a ver com alguma influência que eu pudesse ter tido como orientador. $O$ fato é que o autor da monografia decidiu avaliar criticamente algumas teses de um pesquisador brasileiro, desenvolvidas por este num livro publicado há mais de uma década. O livro, por sua vez, tratava das idéias do filósofo francês Aléxis de Tocqueville. O pesquisador brasileiro em questão, isto é, aquele criticado no trabalho, foi justamente o professor convidado para formar parte da banca. Nos quase 20 anos que estou aqui no Brasil, poucas vezes vi alguém criticar as idéias de algum autor, esteja este morto ou vivo. Pois - voltamos à questão dos famigerados papéis - muitos pensam que os trabalhos monográficos, na filosofia, devem se limitar a fazer comentários anódinos sobre o que pensadores de outros continentes, de preferência mortos, publicaram. No auditório em que a defesa teve lugar já tinha ocorrido num ano anterior algo semelhante. Um estudante da graduação teve a ousadia de apresentar, durante a Semana de Filosofia, uma comunicação na qual criticava as idéias que um professor seu tinha publicado num livro. O professor, claro, estava sentado ao lado do estudante, e depois da leitura do texto, houve um debate. Foi uma discussão, como a da defesa da monografia, respeitosa, de alto nível, e, em ambos os casos, os dois professores, apesar de rebater algumas críticas, deram razão ao estudante em vários pontos e reconheceram a pertinência de algumas críticas. Mas os dois casos são exceções, porque se pensa

Educ. e Filos., Uberlândia, v. 22, n. 44, p. 101-114, jul./dez. 2008. 
que o estudante de filosofia brasileiro não pode ousar, não pode ter o atrevimento de querer ser filósofo e se deve contentar com o papel imposto aos medíocres: os de meros comentadores de idéias de pessoas mortas ou ausentes. Pessoas que, de qualquer modo, nunca vão saber o que se diz sobre seus textos e suas idéias. O que é muito conveniente, claro, porque se pudessem ouvir, certamente discutiriam com seus comentadores e, sem dúvida, argumentariam e não concordariam com tudo aquilo se lhes atribui. Nos dois casos mencionados, tanto o estudante da graduação, como o que defendia sua monografia de pós-graduação, ousaram romper com os papéis que a tradição acadêmica brasileira lhes impôs. Bem por eles, bem para o possível início da criação filosófica no Brasil.

\section{De monografias e incertezas}

Platão e Descartes são decisivos na constituição e fortalecimento - ou talvez seja melhor dizer 'sacralização' - de um modo particular de se conceber o pensamento filosófico. Tanto o filósofo grego como o francês procuraram aproximar a filosofia do tipo de raciocínio que ocorre nas provas geométricas. Procura-se a verdade indubitável partindo-se de princípios evidentes, incontestáveis, sendo o rigor lógico o que garante o passo destes para as conclusões. Nos diálogos de maturidade do filósofo grego, os interlocutores de Sócrates reconhecem que, em alguns casos, os argumentos parecem incontestáveis. Mas afirmam que, mesmo assim, os fatos mostram que as coisas não funcionam como exigiria o argumento. Nas Meditações de Descartes, por exemplo, somos levados por um processo lógico aparentemente impecável à afirmação de que as dúvidas são resolvidas por uma verdade que diz o filósofo ser mais evidente que todas: a de que Deus existe! Há, num e noutro caso, problemas sérios. Pois por que alguém continuaria a duvidar das teses de Platão ou de Descartes se as coisas fossem tão evidentes como eles pensam que são? $\mathrm{O}$ fato é que começamos a refletir filosoficamente quando chegamos ao reconhecimento de nossa ignorância e dos problemas que dela se derivam. O que nos leva ao sentido próprio da palavra 'pesquisa'.

Educ. e Filos., Uberlândia, v. 22, n. 44, p. 101-114, jul./dez. 2008. 
Se alguém pesquisa é justamente porque está procurando algo que não está ao seu alcance, de algo oculto, desconhecido. $\mathrm{O}$ dicionário Houaiss traz no verbete 'pesquisa' o seguinte: "conjunto de atividades que têm por finalidade a descoberta de novos conhecimentos no domínio científico, literário, artístico etc." Quem pesquisa, naturalmente, o faz para conseguir conhecimentos que não tem. Nesse sentido, o que está por trás da pesquisa é uma dúvida, um problema. Mais tarde, o reconhecimento de um determinado problema nos levará a postular hipóteses que esclareçam as dificuldades, que sugiram o caminho para sua solução, que expliquem por que não teriam solução etc.

É isto que deveríamos encontrar nas pesquisas no ensino superior: a especificação do problema, um argumento que mostre que aquilo é de fato um problema e, em seguida, uma hipótese ou um conjunto de hipóteses que levariam o pesquisador à solução do seu problema.

Dessa forma, o que vemos por trás de toda pesquisa é uma incerteza, não uma certeza. O fato é que não há esse ponto de referência arquimediano inamovível nem aquele fundamento absoluto que Descartes postulava. Se houvesse só certezas, não precisaríamos pesquisar. Pesquisamos porque não sabemos ou, melhor, por termos consciência de que há algo de fundamental importância que não sabemos.

Todo semestre, professores universitários do mundo inteiro passamos por um extenso processo de avaliações dos nossos estudantes. E entre essas avaliações temos as monografias de final de curso.

Há pouco tive a alegria de estar presente em duas defesas de monografia de graduação. Numa delas, a graduanda defendia uma tese contrária à que Marx propõe no Prefácio de Para a Crítica da Economia Política. Argumentava ela, em poucas palavras, que a célebre tese do Prefácio - a de que é da relação dialética entre o desenvolvimento das forças produtivas e as relações sociais de produção que a história avança - não é verificada em todos os períodos históricos de transição nem em posteriores análises de Marx. O problema não era, como muitos talvez tivessem esperado 
que fosse, a mera compreensão do que Marx quis dizer. O problema era outro: saber, em primeiro lugar, se uma tese mantida por ele era verdadeira ou não, e, em segundo lugar, se Marx foi consistente com essa tese ao longo de seu trabalho intelectual. $\mathrm{O}$ início da pesquisa, portanto, não e uma certeza, mas uma dúvida, uma discordância, um problema.

$\mathrm{Na}$ outra monografia, a formanda avaliou teses de Aléxis de Tocqueville e terminou com novas dúvidas. Dúvidas que teve a coragem de assumir e justificar nas suas conclusões. Pois uma pesquisa pode nos levar a resultados mais ou menos claros e seguros, mas também poder-nos-ia levar a novos problemas, novas dúvidas e, naturalmente, a novas incertezas. Novas incertezas que motivarão novas pesquisas, nesse nosso destino de sempre estar descobrindo incertezas nas certezas alheias e tumulto onde outros só vêem tranqüilidade.

\section{Autoritarismo, conservadorismo e os pretensos papéis}

Para muitos é difícil entender ou aceitar a pluralidade e lidar com a diferença. O mais fácil, certamente, é dividir o mundo, e as pessoas, em blocos, e dizer que uns são bons, outros maus, uns superiores, outros inferiores. É o maniqueísmo muito útil às posições políticas mais perversas e retardatárias, aquelas que defendem a existência de papéis sociais. Estranho que até agora se levantem vozes conclamando a existência de tais papéis. Pois dificilmente alguém, mais ou menos atento ao que ocorre ao seu redor, não deve ter escutado as vozes de aqueles que querem esmagar os grilhões que representam os papéis que as classes dominantes lhes impuseram. Se não, vamos ouvir o que a comunidade negra no Brasil tem a dizer, ou os índios, ou as organizações de mulheres. Ou haverá alguém que desconheça que a negros e mulheres, por exemplo, lhes impuseram os papéis da subserviência, do trabalho manual e das tarefas domésticas? Ou já ninguém se lembra das épocas em que, se negros ou mulheres pretendiam estudar, professores podiam negar-se a têlos como estudantes precisamente com o argumento de que não

Educ. e Filos., Uberlândia, v. 22, n. 44, p. 101-114, jul./dez. 2008. 
era papel deles educar pessoas inferiores, nem o papel destas, pessoas inferiores, estudar.

O fato é que, individualmente, não somos iguais, nem formarmos parte de grupos homogêneos. Só poderíamos atribuir papéis iguais àqueles que porventura fossem iguais. Mas não somos. E lidar com a diferença e com a heterogeneidade é muito difícil para quem está acostumado a ver o mundo com os olhos da tradição. A visão de atribuir papéis de comando ao homem e de obediência à mulher, se defendida hoje, só poderia ser sintoma de alguém que viva ainda no passado. Num passado em que talvez muitos gostariam de viver.

Afortunadamente, o mundo mudou. E muitas mudanças, precisamente, foram resultado da luta daqueles que não aceitaram mais cumprir os papéis impostos pelos donos do poder, pelas classes dominantes, por todos aqueles que queriam a manutenção de relações obsoletas e de princípios retrógrados que assegurassem e justificassem seus privilégios.

É grave defender uma submissão intelectual com base num óbvio sentimento de inferioridade. Devemos aceitar nossa menoridade intelectual e ver nossos estudantes como incompetentes? Vê-los como incapazes de compreender o que os clássicos da filosofia disseram e, ainda mais, impedidos por tal suposta incompetência de avaliar o que disseram?

Os estudantes brasileiros, sejam do nível médio, sejam do superior, segundo essa perversa visão, não estariam em condições de compreender, pior ainda criticar, esta tese de um dos grandes da filosofia: "Não é apenas necessário, mas também vantajoso que haja mando por um lado e obediência por outro; e todos os seres, desde o primeiro instante de seu nascimento, são, por assim dizer, marcados por natureza, uns para comandar, outros para obedecer." Isto diz um dos maiores filósofos de todos os tempos, Aristóteles, no Livro I da sua Política. Será que há algo nesse trecho que esteja obscuro ou que fique além de qualquer possibilidade crítica de algum ser humano medianamente inteligente? Veja-se se há algo de misterioso e incompreensível neste trecho de Platão que impeça qualquer pessoa equilibrada de entender e questionar:

Educ. e Filos., Uberlândia, v. 22, n. 44, p. 101-114, jul./dez. 2008. 
"Portanto, estabelecerás na cidade médicos e juízes da espécie que dissemos, que hão-de tratar, dentre os cidadãos, os que forem bem constituídos de corpo e de alma, deixarão morrer os que fisicamente não estiverem nessas condições, e mandarão matar os que forem mal conformados e incuráveis espiritualmente". ${ }^{2}$ Para alguns, afirmações como estas, por serem de dois pilares do pensamento filosófico, por serem ditas há mais de dois mil anos, e por sermos, pretensamente, uma sociedade de medíocres, estão fora do alcance compreensivo e crítico de estudantes e professores brasileiros. $\mathrm{O}$ nosso papel, mais uma vez, seria a de assumir nossa menoridade intelectual. Será mesmo? Devemos, então, aceitar que o papel do homem é mandar na mulher, do branco mandar no negro e do médico e do juiz se livrar dos que nascem com algum defeito, mandando prender ou ordenando matar?

\section{Referências}

ARISTÓTELES. A Política. São Paulo : Martins Fontes, 2000. Tradução de Roberto Leal Ferreira.

FEYERABEND, P. Against Method. London : Verso, 1982.

PLATÃO. República. Trad. de Maria Helena da Rocha Pereira. Lisboa : Fundação Calouste Gulbenkian. $7^{\mathrm{a}}$ Ed., 1993.

Data de Registro: 22/05/08

Data de Aceite: 30/06/08

2 Aristóteles. A Política. São Paulo : Martins Fontes, 2000. Tradução de Roberto Leal Ferreira. Platão. República. Lisboa : Fundação Calouste Gulbenkian. $7^{\mathrm{a}}$ Ed. Tradução de Maria Helena da Rocha Pereira.

Educ. e Filos., Uberlândia, v. 22, n. 44, p. 101-114, jul./dez. 2008. 


\title{
SÓCRATES, LA FILOSOFÍA Y SU ENSEÑANZA. ACTUALIDAD DE UNA INVENCIÓN
}

Walter Omar Kohan*

\begin{abstract}
RESUMEN
La filosofía nace con Sócrates. Mejor, nace una filosofía, relacionada a cierta circulación del pensamiento y la palabra. Y nacen también algunos desafíos. Porque el nacimiento de la filosofía gestado por Sócrates excede su tiempo y nos dice relacionado a nuestro presente; si el lector es un profesor de filosofía, diríamos también que con Sócrates la filosofía nace envuelta en una serie de paradojas que ayudan a pensar sus condiciones y límites. En este texto nos proponemos pensar algunos de esos desafíos, sin la pretensión de dar cuenta de una figura histórica sino a la busca de un interlocutor primero, un inicio para pensar nuestro presente.
\end{abstract}

Palabras clave: Enseñanza de la Filosofia.. ignorancia. Sócrates. Foucault

\begin{abstract}
The philosophy is born with Socrates. Best, a philosophy born, some related to movement of thought and word. And also some challenges arise. Because the birth of philosophy evolved by Socrates exceeds its time and tells us connected to our present; if the reader is a philosophy teacher, we would say also that Socrates philosophy born wrapped in a series of paradoxes that help thinking about their conditions and limits. In this text we intend to think

\footnotetext{
* Doutor em Filosofia, com Pós-Doutorado na Universidade de Paris VIII. Professor na Universidade do Estado do Rio de Janeiro. Pesquisador do CNPq e do Prociência UERJ/FAPERJ. E-mail: walterk@uerj br
} 